\section{Holocene Climate in the Alps: Toward a Common Framework?}

\author{
Aix les Bains, France, 15-18 Jan. 2004
}

One of the main issues about forecasting climatic change concerns its meso-scale effects and possible implications for populations in sensitive areas. Among them, the mountains, and particularly the European Alps, merit special attention due to

1) their role as a climatic barrier as well as a biodiversity refuge

2 ) their role as a water resource area, and

3) because they are the most inhabited mountainous area in the world.

The French Mountain Institute, within the framework of its program "Climate variability in mountainous regions", sponsored the ClimAlp' workshop aimed at drawing an overview of the climate changes that affected the alpine range through the Holocene. The French Mountain Institute aims to bring together researchers, economic leaders and environmental managers, as well as policy makers, who deal with the specific problems of the sustainable development of mountain areas. Fifty scientists from 7 European countries were brought together to present climatic and environmental reconstructions using a wide range of archives (glaciers, peats, lakes, speleothems and tufa concretions, tree rings, historical sources) and proxies (biotic indicators, detrital fluxes, isotopes, landform processes, etc.).

One of the strong points of the meeting was the coming together of such a rich diversity of researchers usually working in different communities. A general scheme emerged as a first step toward a synthesis of our current knowledge concerning Holocene climate variability in the Alps.

A national division of knowledge and skills was noticeable. This geographical fractionation precludes the establishment of a real common framework describing the meso-scale evolution of climate over the Alps. Only the pollen community was able to establish a regional synthesis, mainly thanks to the existence of pollen databases. They presented a detailed temperature reconstruction on a high-resolution time-step of 100 years at the scale of the Alps. This reconstruction evidences narrow temperature changes over the Alps over the last 8,000 years. This is confirmed by punctuated reconstructions from chironomids, tree rings and oxygen isotopes (measured on ostracod valves), which present a similar overall pattern.The "ClimAlp" Map" showing the location of all the climate reconstructions presented during the ClimAlp' workshop and covering the whole European alpine range.

This weak temperature variability contrasts with evidence of glacier fluctuation, as well as changes in hydrological fluxes resulting in lake level fluctuations, together

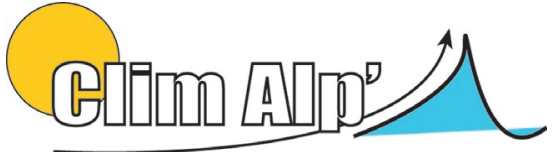

with changes in intensity and frequency of major floods of alpine rivers. Hence, Holocene climate variability was certainly driven in large part by changes in precipitation. A study of meteorological archive data covering the last five centuries suggests that changes in moisture export by westerlies from the North Atlantic Ocean were one of the main modes of this variability.

Although the Holocene appears to be a relatively stable climatic period all along the alpine range, these weak changes probably impacted the alpine populations. The case of perilacustrine dwelling desertion due to lake-level rises is now well constrained in the French Jura and Swiss Plateau. A different aspect of the impact of climate change on human environments is being addressed by the emerging field of research dealing with massive landslide movements. Their climatic significance and triggering conditions need to be studied as they appear to be related to

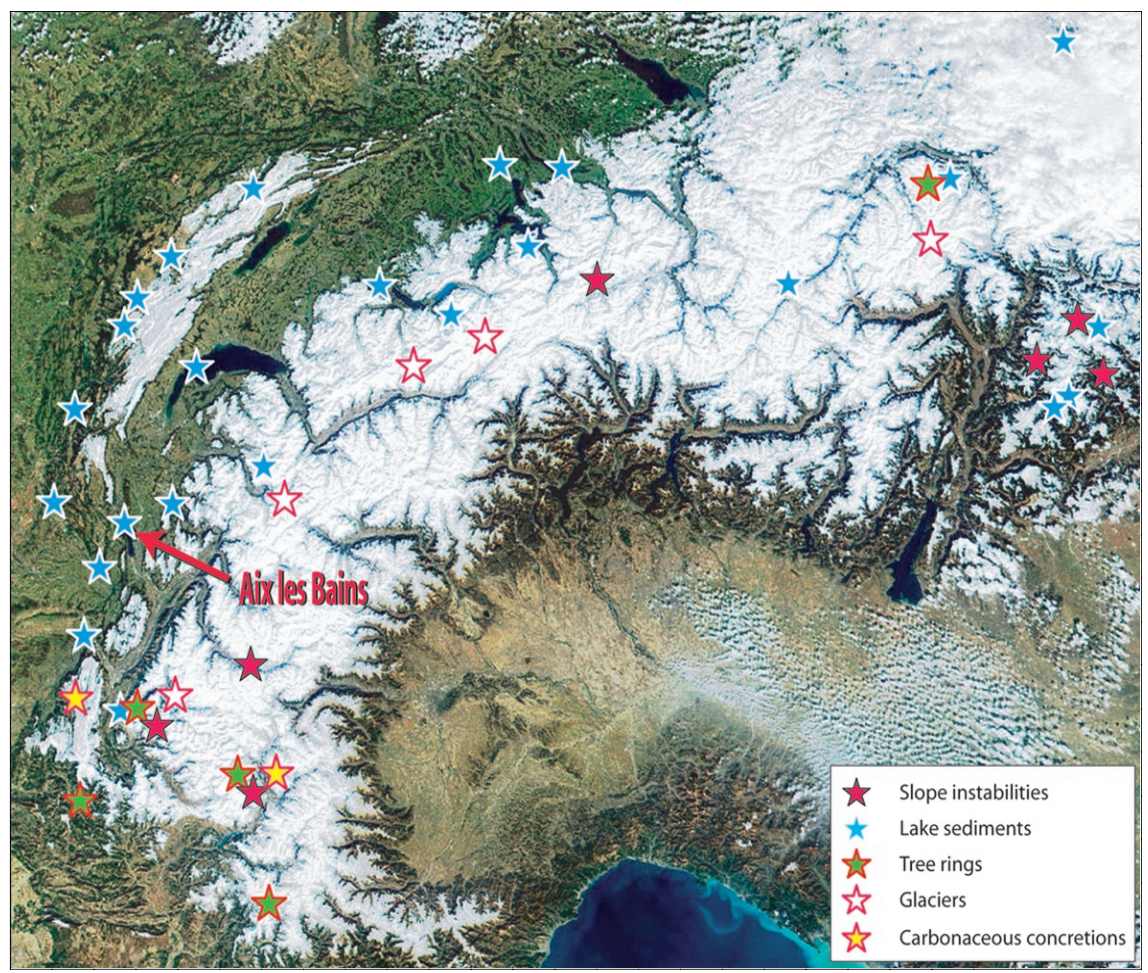

The "ClimAlp" Map" showing the location of all the climate reconstructions presented during the ClimAlp' workshop and covering the whole European alpine range. 
climate change and are a potential future consequence of presentday climate warming. Conversely, alpine populations also impacted their own environment, at least since the Bronze Age, through changes in land-use resulting in increasing sediment fluxes, deliveries to lake basins and changes in the flora and fauna.

The complexity of the retroactions between humans, climate and natural systems makes it difficult to disentangle the human and climate fingerprints from the majority of the natural archive records. This points to the necessity of increasing collaboration between archaeologists and paleo-environmentalists and to work with the largest proxy panoply. Consequently, it was decided to continue this regional, pluridisciplinary approach and the workshop gave birth to the "ClimAlp' Initiative", whose objective is to facilitate exchanges within the community-mainly via a list-server-the construction of a database and the support of further meetings.
Marc Desmet, Fabien Arnaud

Université de Savoie Le Bourget du Lac, France

marc.desmet@univ-savoie.fr

MARIE-Antoinette MöLIÈres

LGGE, Saint-Martin d'Heres, France

Emanuel Chapron

Geological Institute, ETH Zürich, Switzerland

\section{Climalp members}

www.institut-montagne.org

\section{Indian Monsoon and Holocene Climate Variability}

\section{BangaloRe, INDIA, 17-18 May 2004}

The Geological Society of India (Dr. B.P. Radhakrishna, President) organized an International Workshop from 17-18 May 2004 in Bangalore, India, sponsored by PAGES, the Department of Ocean Development (New Delhi), the Department of Science and Technology (New Delhi), and the Indian Space Research Organization (Bangalore). The workshop was well organized by $\mathrm{R}$. Shankar from Mangalore University and centered around the following three themes: Holocene climate series from marine records (Arabian Sea and Bay of Bengal; 7 invited talks); continental records (lake/tank sediments, stalagmites, peats, river floods; 9 invited talks); and monsoonal rainfall variability and prediction (3 invited talks). About 55 Indian scientists and 6 scientists from Bangladesh, Germany, Sweden and the USA attended the meeting. The wide opportunity for informal discussions between the scientists during tea breaks, meals and poster sessions, the pleasant ambience of the conference hall and guesthouse of the National Institute for Advanced Studies (NIAS), set amidst a peaceful flowery park, and the exquisite South Indian cuisine, as well as a cultural program featuring expressive dances with ancient Hindu religious themes made this workshop a memorable experience for all participants.

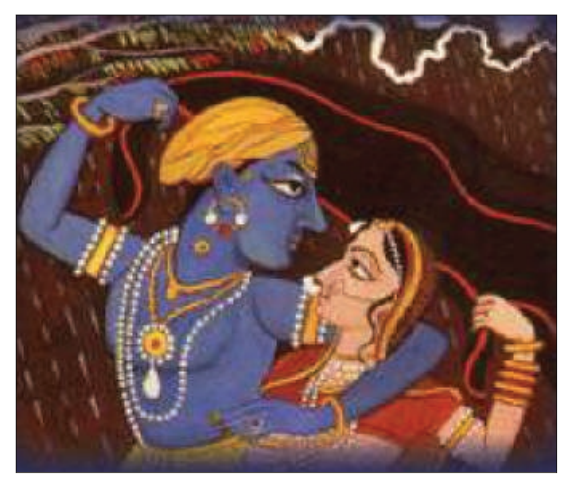

Fig. 1: Indian miniature showing a male Monsoon donating rain and fertility, as a symbol of life and love, to a voluptuous woman.

Highlights were the talks on "The Indian Monsoon as a Component of the Climate System during the Holocene" (R.R. Kelkar), "Has the Winter and Spring Rain over NW India and Pakistan changed during the Holocene?"(M. Staubwasser), "Luminescence Chronometry of Land Records and Palaeomonsoon Reconstruction: Applications and Implications" (A.K. Singhvi), "Summer Monsoon Rainfall Variability Recorded in Stalagmites from Oman and Yemen" (D. Fleitmann), and "Holocene Precipitation and Monsoon Theories" (J. Srinivasan). After peer review, papers will be published in a Special Issue of the Journal of the Geological Society of India.

During the concluding session, achievements and new avenues of research were outlined. The need for closer collaboration between the various Indian working groups and the Department of Science and Technology was stressed, as well as the need for improved cooperation between Indian scientific institutions and the international community (which in the marine realm is still hampered by the inaccessibility of the Indian EEZ to non-Indian research vessels).

Once again, the need for more long-term, high-resolution marine, coral and continental records on a decadal (or even sub-decadal) level was emphasized. New dating techniques should be developed and applied (e.g., luminescence chronometry) and existing ones, such as ${ }^{14} \mathrm{C}$ dating, calibrated with new reservoir ages.

Major open questions include:

How can we define "monsoon intensity" (wind strength, rainfall, temperature)?

Can we define better proxies for winter versus summer monsoon, as well as for sea surface salinity?

Can we link terrestrial and marine archives?

\section{ULRICH VON RAD \\ Hannover, Germany \\ u.vonrad@t-online.de}

